\title{
Draft Fan Control using Fuzzy Logic in Thermal Power Plant
}

\author{
P. Sakthi, P. Yuvarani, S. Kiruthika
}

\begin{abstract}
In a thermal power plant combustion process in the boilers plays a vital role and it has to be controlled effectively. At present, this is controlled using draft fans employed with DCS. This paper deals with the controlling process using Fuzzy logic. The goal of this task is to manage the Forced draft fan, Secondary air fan, Grid refining fan and induced draft fan in the boiler. Every one of these fans assume a significant job in controlling the temperature of the boiler during the burning (combustion) procedure. Utilizing DCS to control the temperature is mind-boggling expense and furthermore it needs a different server, a processor and a workstation to complete the procedure. In the case of software based Fuzzy logic controller, the controlling process is the cheapest and the easiest method to maintain and control.
\end{abstract} FLC

Keywords: Boiler Furnace, SA Fan, ID Fan,FD Fan,SA Fan,

\section{I .INTRODUCTION}

The forced draft fan[4] is utilized to keep up the climatic air inside the boiler for doing the combustion procedure. An induced draft fan is used to suck the flue gases generated in the boiler. It helps to maintain the required pressure. Thus the temperature inside the furnace is maintained by an induced draft fan[4] and a forced draft fan [4]. At the point when the humidity of the fuel is expanded, the temperature gets diminished [1]. In the mean-time it is necesary to increase the speed of rotation of the fan. A secondary air fan (SA fan) is used in the boiler to increase the speed. To reduce the unburned fuel in the boiler the Grid refining fan is used (GR Fan) [7].This paper clearly explains about the controlling of the speed of the draft fans used in the boiler in accordance with the presence of humidity level in the fuel and also the oxygen content in the boiler.

\section{II . FURNACE IN THERMAL POWER PLANT}

Furnace is the important part in the boiler. It produces required heat in order to produce steam inside the boiler. The fans involved in furnace operation is forced draft fan, induced draft fan, grid refining fan and secondary air fan. Heater temperature inside the boiler is kept up with assistance of a Forced Draft fan [FD] and an induced Draft fan [ID].In furnace a travelling grate is present which is used to move the fuel inside the furnace. In furnace, a Grid Refining fan [GR] is used to recycle the unburned coal inside the boiler.The Secondary Air fan [SA] is used to provide additional air to the furnace for the combustion process. Ash is collected in the ash hopper and it is carried along with the fuel used in the furnace. Coal is used in order to produce required heat for the production of steam inside the boiler in the thermal power plant [2]. In the ash conveyor water is used to carry the ash.

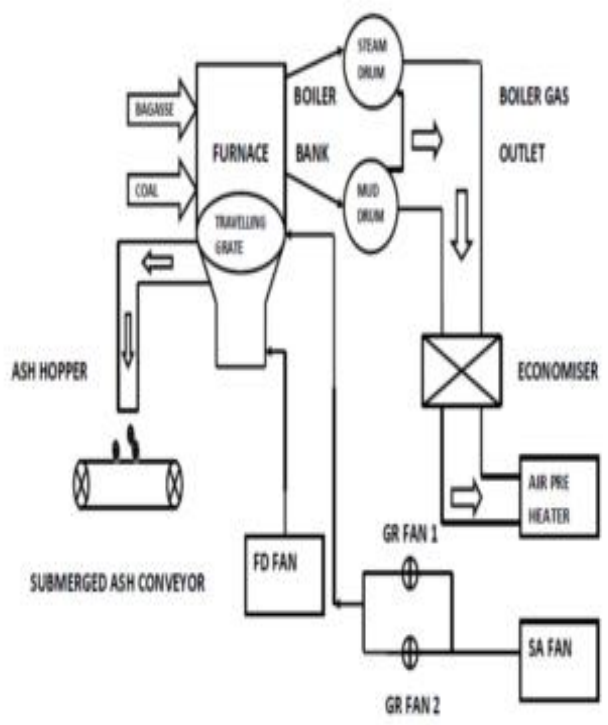

Fig 1 Furnace Operation

\section{FORCED DRAFT FAN[4]}

A FD fan is utilized to supply ignition air into the framework. The working range of this fan is usually above atmospheric pressure. The Forced draft fan is utilized to give important oxygen to the burning procedure.Control is accomplished by regulating the fan speed or damper operation [3]. The Fig 2 shows that the location of the FD fan in the boiler. Care should be taken that the Forced draft furnace must be airtight in order to avoid the outflow of flue gases around the neighbouring area.

The FD fan is associated with the base of the heater.It makes the fuel combustion in an efficient manner. Either steam turbine or electric motor is used to drive the Forced Draft fan.
Revised Manuscript Received on August 14, 2019.

P.Sakthi, Department of Electronics and Instrumentation Engineering, M.Kumarasamy College of Engineering Karur, Tamilnadu, India (Email: Sakthi.npi@gmail.com)

P. Yuvarani, Department of Electronics and Instrumentation Engineering, M.Kumarasamy College of Engineering Karur, Tamilnadu, India.

S. Kiruthika, Department of Electronics and Instrumentation Engineering, M.Kumarasamy College of Engineering Karur, Tamilnadu, India.

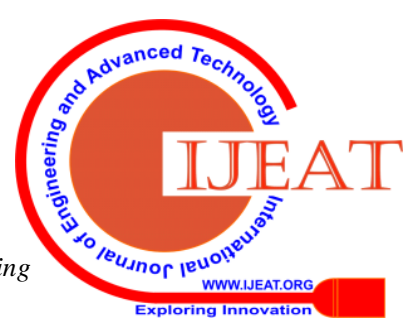




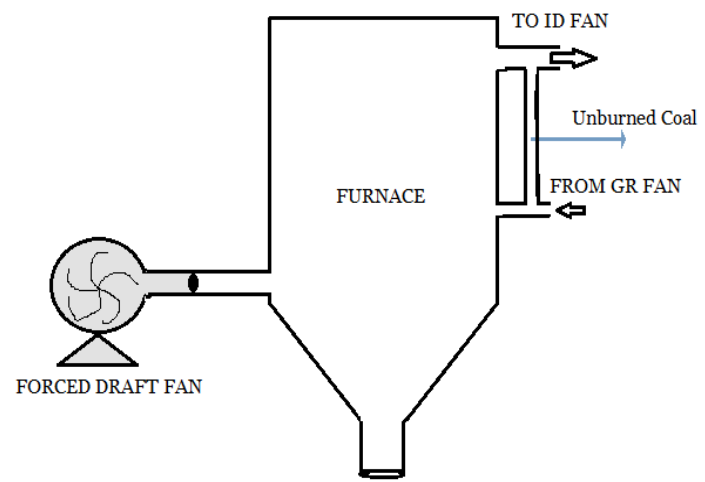

Fig 2 Forced Draft Fan[4]

\section{INDUCED DRAFT FAN[4]}

An ID fan goes about as a vacuum pump which is introduced among boiler and stack [4].The flue gases from the boiler are sent to the atmosphere through this fan. The system is controlled by regulating the speed of a fan. It is connected at the top of the boiler. The pressure present in the furnace is somewhat lower than the pressure in the atmosphere [5].In this type of fan a negative air pressure is maintained to avoid backfire. In order to prevent the air leakage in the boiler, the casing and the opening of the Boiler are sealed properly. The unlocked packaging may bring down the limit and proficiency of the fans. The Fig 3 shows that the location of ID fan in the boiler.

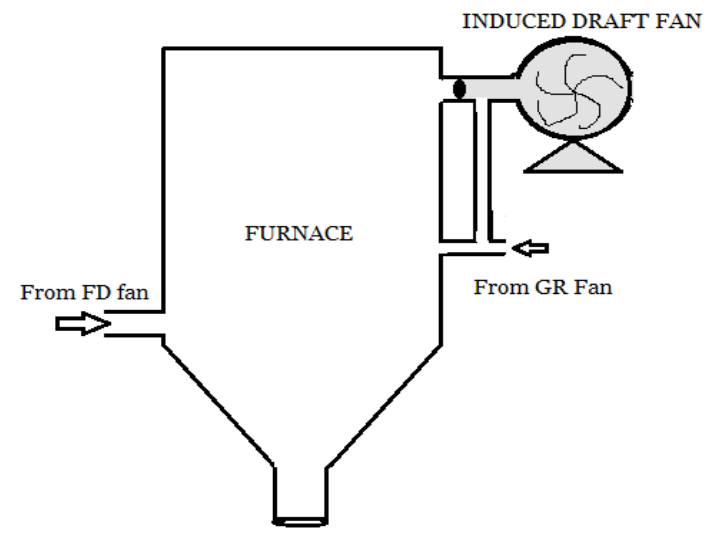

Fig 3 Induced Draft Fan

The boiler[4] packaging is basic to be manufacture sufficiently able to withstand the outside weight of the air.

\section{SECONDARY AIR FAN AND GRID REFINING FAN}

It is placed in the middle of the boiler. The grid refining fan is mainly used for the re-combustion of unburned fuel to the boiler which makes to reduce the wastage of coal from the boiler. Due to this there is less scarcity of coal and also it reduces the cost of coal. The GR fan gets its input air from the secondary air fan. So the outlet pressure from GR Fan is low when compared to Secondary Air Fan [6].

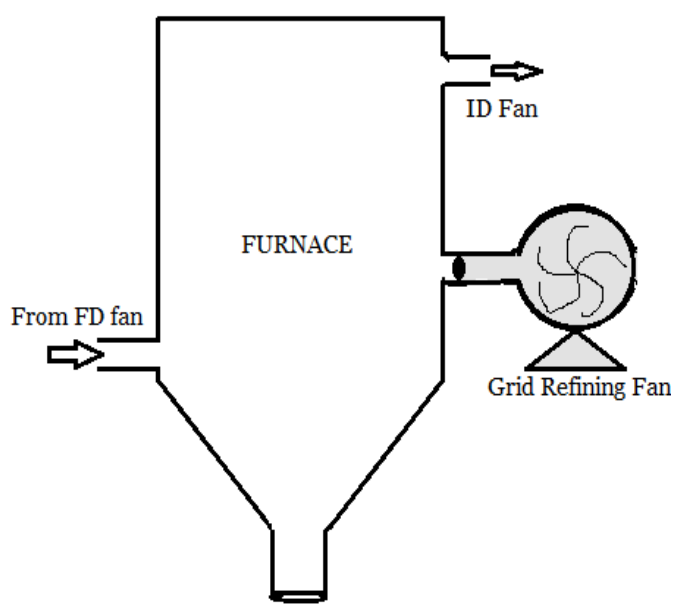

Fig 4 Grid Refining Fan

The Fig 4 demonstrates the area of GR fan in the evaporator. It is put at the base of the heater. The optional air fan is chiefly utilized for sending the additional air supply to the kettle. So the burning in the evaporator happens consistently without the loss of heater temperature. The wellspring of the SA Fan is from the yield of FD draft fan [6].So the outlet weight from the SA Fan is similarly low contrasted with the FD Fan.

\section{FUNDAMENTAL BLOCK DIAGRAM OF FURNACE}

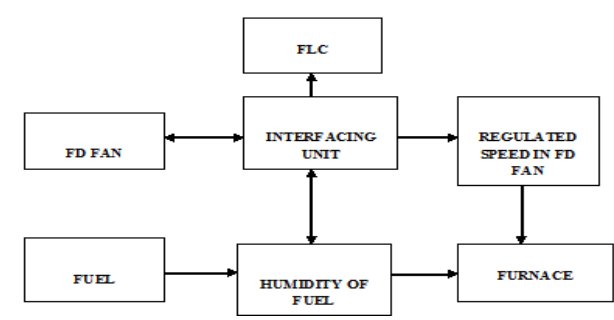

Fig 5 Furnace Block Diagram

The fig. 5 demonstrates the interfacing of equipment with Mat lab programming.The communication cable is used as a interfacing cable between the hardware devices and the software. The humidity sensor output is as the input to the software and thus the fans will be controlled.

\section{PID CONTROLLER}

In the industries, for controlling the process variables PID control is most widely used [7]. The change in the actual value and the measured value of the controlling variable is calculated as error value.The utilization of the controlled variable is to modify the procedure to limit the mistake. The PID controller calculation includes three separate consistent parameters, the corresponding, the basic and the subordinate 
qualities, meant as P,I and D [8].In PID control the relative control relies upon the present blunder, Integral control relies upon the amassing of past mistakes and Derivative control relies upon the expectation of future blunders, in view of current rate of progress.

\section{FUZZY LOGIC CONTROLLER[12]}

The Fuzzy Logic Controller[12] Algorithm can be well explained by the term Fuzzification, Defuzzification, Inference Engine, etc. The fuzzy logic system chosen for the draft fan controlling process has multiple input and single output. This system has $n$ variables $A_{1}, A_{2}, \ldots A_{n}$. The control action can be well explained by the "if-then" rules and the input variables are first transformed into their linguistic variables [9]. The process of converting the input variables into their respective linguistic variables through different membership functions is called fuzzification. It is the first process in the inference engine.

In the inference process, the output is determined by the linguistic values (fuzzified output).The process of converting the fuzzified output into a crisp value is called Defuzzification [10]. In this architecture all the rules are evaluated to produce the final fuzzy value which is converted into a crisp set by defuzzification process. The combination of fuzzy inputs and the generated outputs are done with product operation or sum operation respectively. In the Fuzzy Logic Controller the defuzzified value is used to control the required process. Some of the Defuzzification methods used are [12]:

- $\quad$ Centre of Sums Method(COS)

- $\quad$ Centre of Gravity(COG)

- $\quad$ Centre of Area (COA)

- Maxima Methods

In this paper we have used Centre of area method (COA). The triangular fuzzy sets are utilized for information sources(inputs) and yields (outputs). The entire fuzzy logic controller is dependent on the fuzzification, Defuzzifictaion and the knowledge base. The FLC is based on the following constraints.

Constraint 1: The triangular fuzzy sets are used in the fuzzification process.

Constraint 2: For each adjacent fuzzy set the width is extended to its peak value. The addition of the membership values over the gap between two adjacent sets will be one. Over the universe, the sum of all the membership functions at any time for a control variable will be one and it is called as fuzzy partition [11].

Constraint 3: The Centre of area method is used as the defuzzification method which is same as that of the method used to obtain the weighted average of all output values [12].

\section{SIMULATION RESULTS}

This paper clearly explains about the operation of Induced draft fan [4], Forced draft fan [4], Secondary air fan and Grid refining fan.

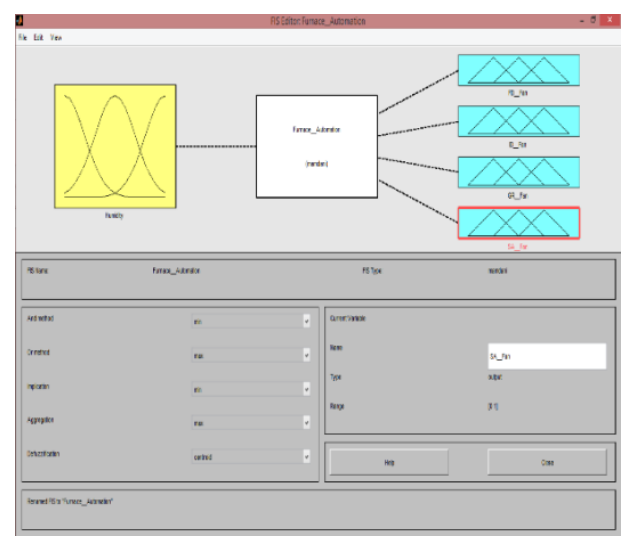

Fig 7.FIS Editor Window

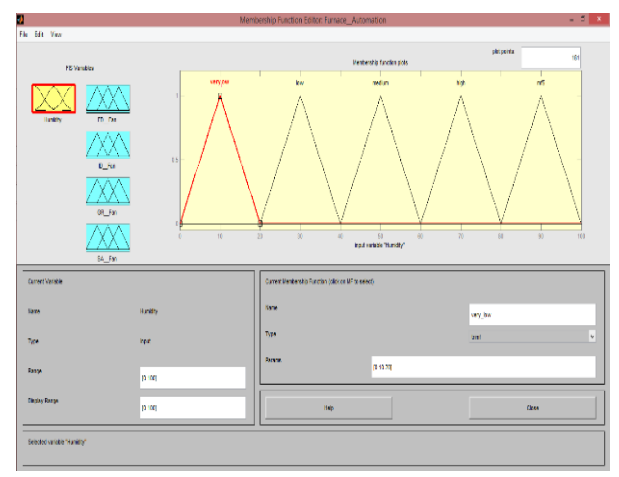

Fig 8 Input Humidity

As indicated by the stickiness of fuel and oxygen content in the boiler the progression of air will be controlled. Here the information parameters are humidity, speed of the transport line and the oxygen content in the boiler. The yield parameters are speed of the incited draft fan, speed of the constrained draft fan and the speed of the auxiliary air fan. The fig 7 is a FIS manager, fig 8 is a contribution to the framework (Humidity input),fig 9 is the FD fan yield and Fig 10 is an ID fan yield in the Fuzzy rationale controller.

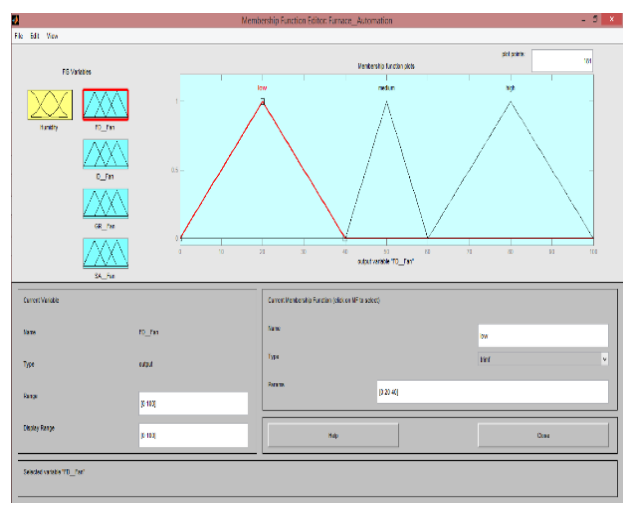

Fig 9.FD fan output 


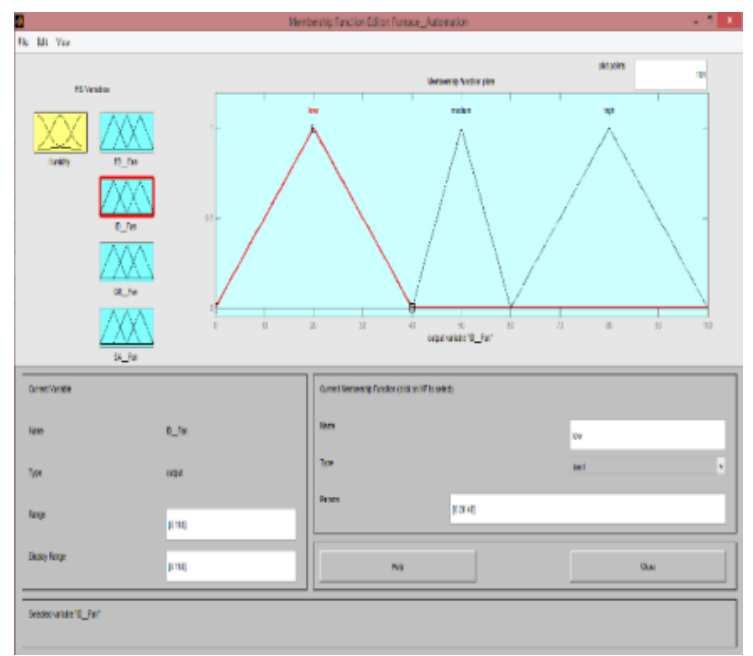

Fig 10 D fan output

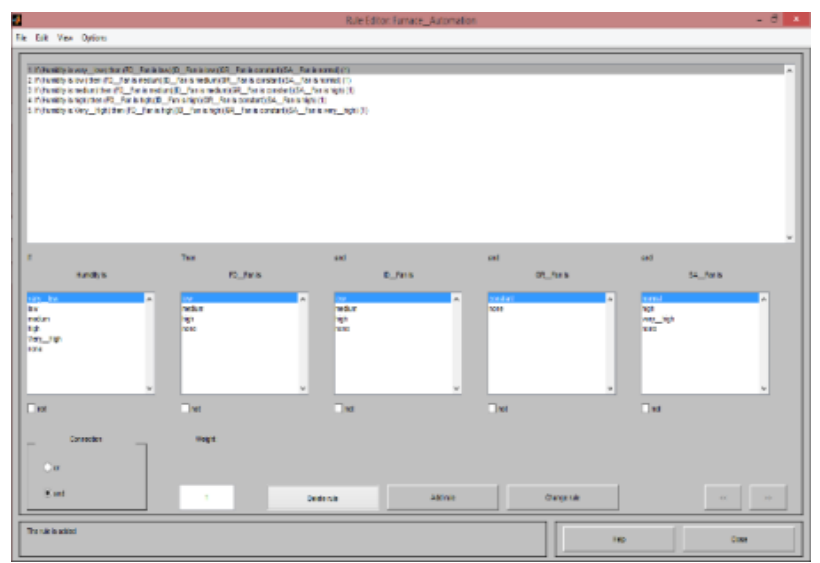

Fig 11 If then Rule

As indicated by the humidity and speed of the transport line, the speed of the draft fans will be controlled. On the off chance that the humidity gets expanded the speed of the FD fan will be expanded. On the off chance that the speed of the FD fan gets expanded the weight in the heater will increments. So for lessening the pressure in the boiler the speed of the ID fan ought to be expanded.

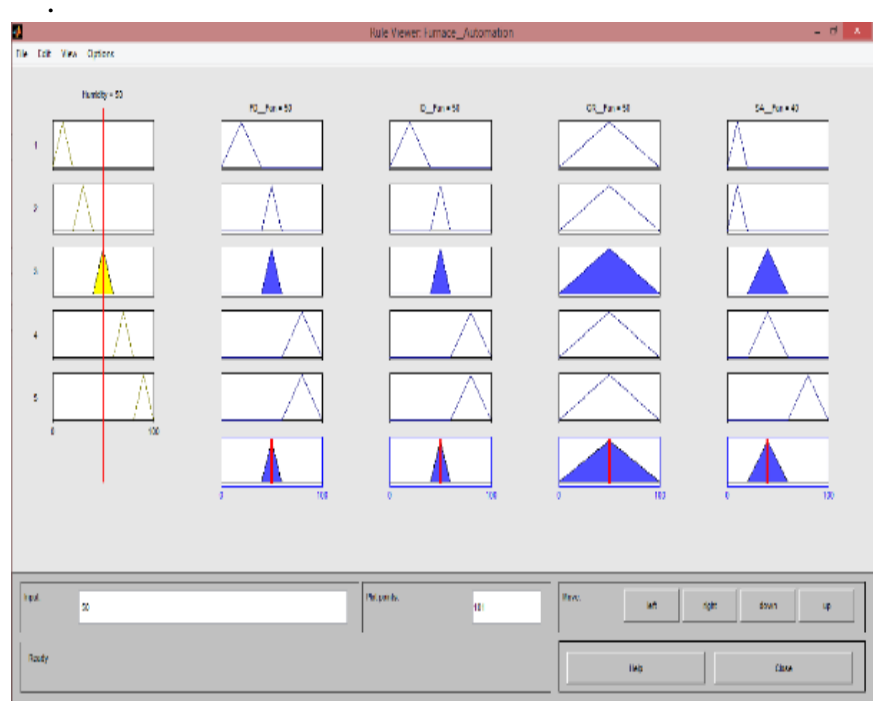

Fig 12 Rule viewer output

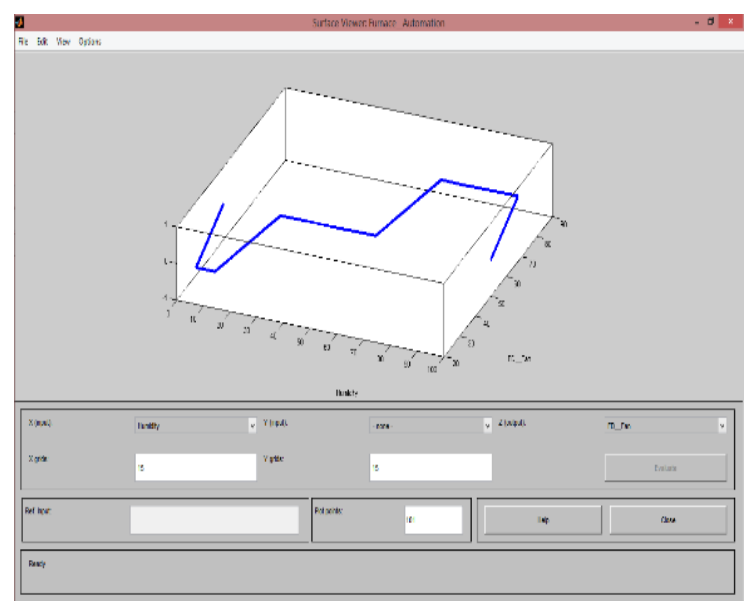

Fig 13 Surface viewer output

The fig 11 demonstrates the guidelines given to the FLC and the fig 12 demonstrates the Rule viewer output and the fig 13 demonstrates the Surface viewer output.

\section{CONCLUSION}

It is clear that the FLC can be utilized to control the combustion procedure in thermal power plant.Thus the proposed method is proved to be efficient and cost effective. It is implemented in the Coal and Bagasse based Thermal power plant at EID Parry Sugar India Limited, Karur with the existing method of controlling the boiler using DCS system.

\section{FUTURE SCOPES}

Fuzzy logic control is an efficient intelligent controlling method used for linear and non linear systems. So far the traditional controllers are used for controlling temperature in the boiler. The disadvantage is that it produce errors when there is a variation of load and nonlinearity in the system. But an intelligent control system can be easily implemented in boiler and other steam temperature control and water level control applications.

\section{REFERENCES}

1. Hamid Bentarzi, Rabah Amr Chentir Nadir Belaidi Samah Dif And Nikos E.Mastorakis, "A New Approach Applied to a Thermal Power Plant Controller Using Fuzzy Logic" Issue 9, Volume 6, September 2009.

2. D. D. Ivezić and T. B. Petrović, "Robust IMC Controllers with Optimal Set points Tracking and Disturbance Rejection for Industrial Boiler," Strojniski vestnikJournal of Mech. Engg.,vol. 56, no. 9, pp. 565-574, August2010.

3. K.J. Astrom andR. D. Bell "Drum-boiler dynamics,"Automatica, 36, Elsevier, vol. 4, pp. 363-378, 2000.

4. P.HariKrishnan, V.Ramprasadh, Controlling power plant boiler and draft fan using LabVIEW ,2014

5. F. Morilla, "Benchmark for PID control based on boiler control problem," IFAC Conference on Advances in PID Control, PID'12, Brescia (Italy), March 2012.

6. Y.Guili, L. Jizhen and W. Tianhong, "The Controller Design for the Boiler Drum Level SystemBased on 
Immune,Principle,"Fourth International Conference on Intelligent Computation Technology and Automation, Society of IEEE, vol. 1pp. 532-534, 2011.

7. K. G. Begum, D. Mercy, H. K. Vedi and M. Ramathilagam, "An Intelligent Model Based Level Control of Boiler Drum," IJETAE, vol.3, Issue1, pp. 516521, Jan. 2013.

A. Shome and S. D. Ashok "Fuzzy Logic Approach for Boiler Temperature \& Water Level Control," International Journal of Scientific \& Engineering Research, vol. 3, Issue 6, pp. 1-6, June 2012.

8. Subodh Panda, Ajit Kumar Patro, Dr. (Mrs.) Sarada Baboo,"Adaptive Neuro-Fuzzy Controller For Thermal Power Plant Optimization "Volume 2, Issue 6, November - December 2013

9. Li, Nan; Teng, Fei System Design Electro-motor Rotational Speed Control Based on of Lab VIEW. Computer Measurement \& Control, pp.794-799. 2006.

10. Amuthameena S, Monisa S, , 'Design of fuzzy logic controller for a non-linear system ', Proceedings IEEE international conference on electrical instrumentation and communication engineering, 2017.

11. Uma, J, Jeevanandham, A 2016, 'Investigations of Fuzzy Logic Controller for Sensorless Switched Reluctance Motor Drive', IOSR Journal of Electrical and Electronics Engineering (IOSR-JEEE), Vol. 11, Issue.1,pp. 30-35.

12. Kiruthika S, Sakthi P, Automized Molasses feed control using Programmable Logic Controller, International Journal of Pure and Applied Mathematics, vol.118 Issue. 8 pp,197-200,2018.

13. Ondrej Krejcar, Ivo Spicka, Robert Frishcer, Milan Heger,'Incremental PIC Controller with handled limit states and manual settings", $2^{\text {nd }}$ International Conference on Mechanical and Electronics Engineering,2010 